\section{Risk factors for low birth weight in Rio Grande do Sul State, Brazil: classical and multilevel analysis}

\author{
Fatores de risco para baixo peso ao nascer no \\ Estado do Rio Grande do Sul, Brasil: análise \\ clássica e multinível
}

\author{
${ }^{1}$ Universidade Federal de \\ Santa Maria, Santa Maria, \\ Brasil. \\ 2 Universidade Federal do Rio \\ Grande do Sul, Porto Alegre, \\ Brasil. \\ Correspondence \\ A. B. Moraes \\ Universidade Federal de \\ Santa Maria. \\ Rua Conde de Porto Alegre \\ 1080, apto. 301, Santa Maria, \\ RS 97015-110, Brasil. \\ anaelena.bm@terra.com.br
}

\begin{abstract}
The objective of this study was to identify risk factors for low birth weight in singleton live born infants in Rio Grande do Sul State, Brazil, in 2003, based on data from the Information System on Live Births. The study used both classical multivariate and multilevel logistic regression. Risk factors were evaluated at two levels: individual (live births) and contextual (microregions). At the individual level the two models showed a significant association between low birth weight and prematurity, number of prenatal visits, congenital anomalies, place of delivery, parity, sex, maternal age, maternal occupation, marital status, schooling, and type of delivery. In the multilevel models, the greater the urbanization of the micro-region, the higher the risk of low birth weight, while in less urbanized microregions, single mothers had an increased risk of low birth considering all live births. Low birth weight varied according to micro-region and was associated with individual and contextual characteristics. Although most of the variation in low birth weight occurred at the individual level, the multilevel model identified an important risk factor in the contextual level.
\end{abstract}

Newborn Infant; Low Borth Weight Infant; Risk Factors
Anaelena Bragança de Moraes 1

Roselaine Ruviaro Zanini 1

João Riboldi 2

Elsa Regina Justo Giugliani 2

\section{Introduction}

Birth weight is an important indicator of a population's health and is associated with numerous interrelating factors 1 in the infant, mother, and physical environment 2 .

Low birth weight and prematurity are the principal determinants of perinatal mortality, and low birth weight infants are more vulnerable to the impact of environmental and social conditions 1 .

Worldwide, more than 20 million low birth weight infants are born every year, the equivalent of $17 \%$ of all births in developing countries, more than double the rate in industrialized countries (7\%) ${ }^{3}$.

The main causes of low birth weight include infection, maternal malnutrition, and smoking 4 as well as prematurity, multiple pregnancy, high parity, and complications of pregnancy such as preeclampsia. Evidence also shows that other less known environmental factors can affect fetal growth 1 .

Studies on risk factors for low birth weight have been limited to assessing the influence of individual-level factors (of the mothers and newborns), overlooking contextual variables (mothers' neighborhood).

The fact that mothers from the same neighborhood share the same environment and are thus more similar to each other than to mothers 
from elsewhere may also lead to greater similarity in the outcome variable. When this happens, it violates the assumption of independence, and a correlation exists between mothers and infants (level 1) from the same neighborhood (level 2). This problem is even more important when considering explanatory variables from higher hierarchical levels, such that all the units in a neighborhood are exposed identically to the factor 5 .

Contextual or multilevel statistical analysis seeks to combine the analysis of individuals' characteristics with those of the social groups to which they belong. Contextual variables can have independent effects from individual characteristics or modify the way such characteristics affect the health situation 6 .

The point of departure for traditional regression models is that live born infants are independent from each other in terms of birth weight outcome, and all the variables are treated as belonging to the same hierarchical level. To ignore their role in the contextual level can lead to an incomplete understanding of the determinants of low birth weight found in live born infants and in their populations. Contextual variables affect live born infants directly or indirectly through maternal choices and/or conditions. Many individually measured variables are heavily conditioned by social processes. When the data are structured in hierarchies, units in the same group are rarely independent, because they share the same environment and present similar characteristics 5 .

The current study aimed to identify risk factors for low birth weight in live born infants from singleton pregnancies in Rio Grande do Sul State, Brazil, in the year 2003, using two methods, classical logistic regression and multilevel logistic regression, and to compare the results from the two methods.

\section{Methods}

This ecological study included all the micro-regions in Rio Grande do Sul State, where data on the 149,165 live born infants came from the live birth certificates recorded in the State Information System on Live Births (SINASC) for the year 2003, obtained from the Information Technology Department of the Brazilian Unified National Health System (DATASUS; http://www.datasus. gov.br).

The analysis included live born infants whose mothers resided in the state at the time the live birth certificate was recorded and excluded multiple or unknown-numbered pregnancies $(2,917$ live born infants), those lacking information on birth weight on the birth certificate (200 live births), and those with recording errors (178 live births).

Identification of recording errors used classification of live births based on weight and gestational age, adapted by Souza 7 . The adaptation was necessary because the data on gestational age used in the classification were in weeks (24th to $42^{\text {nd }}$ week), and in the SINASC database this information is grouped in weeks $(<22,22-27$, 28-31, 32-36, 37-41, and $\geq 42$ ). According to this classification of errors, weights less than $500 \mathrm{~g}$ or gestational age less than 22 weeks is either incorrect information or pertains to a stillbirth. According to Margotto 8, newborns weighing less than $500 \mathrm{~g}$ or with gestational age fewer than 22 weeks are not biologically viable and should not be included in the SINASC database ?

The study included records of 145,870 live born singleton infants, after the exclusion of 162 records of live births with gestational age less than 22 weeks; weight less than 500g; gestational age from 22 to 27 weeks and weight greater than 1,500g; gestational age from 28 to 31 weeks and weight greater than $2,500 \mathrm{~g}$; gestational age greater than 37 weeks and weight less than 1,500g; and 16 cases with inconsistent data on maternal age and number of children.

Low birth weight was the outcome variable, obtained from dichotomization of birth weight as low $(<2,500 \mathrm{~g})$ versus non-low weight $(\geq 2,500 \mathrm{~g})$.

The following maternal variables were analyzed: age in years (less than 20, or adolescents, 20 to 34 , and 35 or older); parity (none, 1 or 2, 3 or more children, live births or stillbirths in previous pregnancies); maternal schooling in years ( 0 to 3,4 to 11 , and 12 or more complete years of schooling); marital status (married, unmarried); occupation (housewife or other, i.e. working away from home), number of prenatal visits (none, 1 to 6, more than 6); type of delivery (vaginal, cesarean); place of delivery (hospital, other), and gestational age (preterm or $<37$ weeks versus full-term or $\geq 37$ weeks).

The variables pertaining to the newborn were: sex (male, female); skin color (white, other); congenital malformation and/or chromosome anomaly (no, yes).

The contextual variables were obtained from DATASUS, Foundation for Economics and Statistics (FEEdados; http://www.fee.rs.gov.br/feeda dos), and Institute of Applied Economic Research (IPEA; http://www.ipeadata.gov.br).

The indicators used as covariates for the micro-regions, tested in the multilevel models, were: urbanization rate (population living in the urban area as a proportion of the total population); illiteracy rate (percentage of the population 15 years or older and unable to read or write a simple note); 
average years of schooling (ratio between total completed years of study among individuals 25 years or older and number of persons in this age bracket); per capita GDP (market-price gross domestic product divided by the population); poverty rate (percentage of the population with per capita family income less than one half the minimum wage); household density (percentage of persons in households with density greater than 2 , expressed as the ratio between the total number of household residents and the total number of rooms, excluding bathroom(s) and one more room, namely the kitchen); homicide rate (ratio between the number of homicides and the population, per 10,000 inhabitants); hospitalization rate due to assault (ratio between the number of hospitalizations due to assault and the population, per 100,000 inhabitants); workforce participation rate (percentage of the population in the workforce among the working-age population); infant mortality rate (number of deaths in children under one year of age divided by the number of live births in a given geographic space and given year, per 1,000 live births); Family Health Strategy coverage rate (percentage of persons in the population enrolled under the FHS); water supply (percentage of households with running water from the public supply); sanitation (percentage of households with installations connected to the public sewage system); cesarean rate (cesareans as a percentage of all deliveries); rate of 7 or more prenatal visits (percentage of live born infants among mothers with 7 or more visits); supplementary health coverage (percentage of individuals covered by private healthcare or health plans, by place of residence); physician coverage (physicians per 1,000 inhabitants, including medical residents); mean expenditure on primary care (amounts transferred for primary care per inhabitant).

The data were analyzed using both the total number of live born infants and those classified as full-term (defined here as full-term plus postterm). In the group of full-term live born infants, according to Ferraz \& Kallan (1990, apud Costa \& Gotlieb 9), those with low birth weight were defined as small-for-gestational-age live born infants, which consists of a simplified definition of small-for-gestational-age. The analyses used classical logistic regression and multilevel logistic regression.

The association between the maternal and infant-related variables and the outcome (low birth weight) was initially analyzed with the classical methods, which ignore the data's hierarchical structure in the modeling.

Simple logistic regression was used to estimate the odds ratios (OR) and respective 95\% confidence intervals. Selection of the candidate variables for inclusion in the multivariate model was based on p-value $<0.2510$.

Multivariate logistic regression of live births used two analytical strategies: the first, unconditional, simultaneously included in the model all the independent variables that were significant in the simple logistic regression, with the enter method and significance set at $5 \%$; and the second, conditional, which followed a hierarchy for entering the variables into the multivariate model. The latter considered three blocks: distal (schooling, marital status, occupation, and skin color); intermediate (age and parity); and proximal (number of prenatal visits, type of delivery, birth place, gestational age, sex, and congenital anomaly). The conditional backward selection method was used, considering as potential confounding factors the variables selected according to $10 \%$ significance within each block. The subsequent analyses kept in the model those that remained associated with low birth weight, after adjusting for the confounding variables from the same block and hierarchically superior blocks 11 .

Full-term live born infants were analyzed with simple logistic regression and unconditional multivariate regression (enter method), given that the results of the two strategies for live born infants, explained previously, did not differ.

For the multilevel analyses, generalized hierarchical linear models were adjusted with two hierarchical levels to identify predictors of low birth weight, considering the variation among live births (level 1) and micro-regions (level 2). The modeling was performed for all live births and for full-term live births.

This model's response variable $\mathrm{y}_{\mathrm{ij}}$ is binary and is 1 if the $i^{\text {th }}$ live born infant in the $\mathrm{j}^{\text {th }}$ microregion presents low birth weight or 0 otherwise, where:

$\left.y_{i j}=\exp \left(\alpha+\beta X+u_{j}\right) /\left(1+\exp \left(\alpha+\beta X+u_{j}\right)\right)+e_{i j}\right)(1)$

The connection between the predictor variables $(\mathrm{X})$ and the response variable is guaranteed by the logit function, which is a linear function of X or a transform of $\pi$. So, modeling:

$\log \frac{\pi}{1-\pi}=\log$ ito $(\pi)=\alpha+\beta X+u_{j}$

where $u_{j} \approx N\left(0, \Omega_{u}\right)$ is the random effect at the micro-region level. The coefficients are:

$$
\begin{aligned}
& \alpha=\log \frac{\pi_{0}}{1-\pi_{0}} \\
& \beta=\log \frac{\pi_{1}\left(1-\pi_{0}\right)}{\pi_{0}\left(1-\pi_{1}\right)}
\end{aligned}
$$


where $\alpha$ and $\beta$ are the intercepts and slope for the $\mathrm{X}$ variable at the micro-region level for the outcome; $\beta$ is the log of the odds ratio and $\exp (\beta)$ is the OR.

The error term $e_{i j}($ level 1$)$ has a mean of 0 and variance $\sigma^{2}$. Variance $\sigma^{2}$ is usually known as a parameter of overdispersion and its estimate is 1 12. Thus, part of the model's variability is binomial (level 1) and part is normal (level 2) 5,13.

Due to convergence problems with the model, the IGLS algorithm and first order MQL procedure were used to obtain initial estimates, followed by the RIGLS algorithm and second order PQL procedure, as suggested in the literature 5,14.

The modeling first evaluated the null model, without covariates, with the aim of assessing the correlation among micro-regions ( $\rho$ ) or variance partition coefficient (VPC), which expresses the proportion of total variance due to the contextual level. In the multilevel logistic regression, $\rho$ can be estimated by different procedures. This study used the latent variable method, which converts the individual level variance from the probability scale to the logistic scale:

$\rho=\sigma_{u 0}^{2} /\left(\pi^{2} / 3+\sigma_{u 0}^{2}\right)$

where $\sigma^{2} \mathrm{u} 0$ is the variance between the microregions and $\pi^{2} / 3$ is the variance between live births, that is, the variance of a standard logistic distribution 13 .

The contextual indicators were considered continuously, centered on the mean 12 , and categorized by tertiles and quartiles, in order to establish statistical significance.

The contextual variables were tested individually in the null model and later included one by one in the multilevel model containing all the significant variables at level 1 of the classical simple logistic regression for evaluation of significance in the complete model 5

The statistical significance of the coefficients from the fixed and random parts of the multilevel model was evaluated using the Wald test with $5 \%$ significance.

Interaction terms were tested as a function of the significance of the micro-region variable, with significance set at $10 \%$.

One of the criteria for choosing the best model was the reduction in the variance at the contextual level $\left(\sigma_{\mathrm{u} 0}^{2}\right)$. The proportion of level 2 variance explained by the variables included in the model was calculated by:

$V_{\text {exp lained }}=\left(\left(V_{0}-V_{1}\right) / V_{0}\right) \cdot 100$

where $\mathrm{V}_{0}$ is the initial model's level 2 variance and $\mathrm{V}_{1}$ is the final model's level 2 variance.
The correlation between micro-regions $(\rho)$ was calculated for all the adjusted models.

Adjustment of the models was evaluated by the Deviance Information Criterion (DIC), which is a generalization of the Akaike Information Criterion (AIC) and is calculated from a Bayesian estimation using Markov Chain Monte Carlo (MCMC) 13. The lower the DIC value, the better the model.

An analysis of ordered residuals was performed at the micro-region level, which allowed identifying the risk estimates for low birth weight in micro-regions which differed significantly from the overall mean 15,16.

The classical and multilevel statistical analyses were performed with SPSS 13.0 (SPSS Inc., Chicago, USA) and MLwiN 2.02 (Centre for Multilevel Modelling, Bristol, UK) respectively.

The study was approved by the Institutional Review Board of the School of Medicine, Federal University in Rio Grande do Sul, having complied with all the provisions of Ruling 196/96 of the Brazilian National Health Council.

\section{Results}

Mean birth weight was 3,168.75g, ranging from $550 \mathrm{~g}$ to $5,990 \mathrm{~g}$. Prevalence of low birth weight was $8.4 \%$.

Table 1 shows the distribution of birth weight by $500 \mathrm{~g}$ brackets according to gestational age, as recorded in the live birth certificate. The largest proportion of live births (41.4\%) was in the $3,000 \mathrm{~g}$ to $3,499 \mathrm{~g}$ range. Of the full-term live born infants, $4.2 \%$ were low weight.

Table 2 shows the distribution of predictors of low birth weight in live born infants and the results of simple and unconditional multivariate logistic regression.

According to simple logistic regression, all tested variables were associated with low birth weight ( $p<0.001)$. The odds of low birth weight in live born infants of mothers with no prenatal care were 3.79 times the odds of low birth weight in live born infants of mothers with 7 or more visits. The odds of low birth weight in live born infants with congenital anomalies were 3.17 higher than in those without anomalies. The following risk factors were identified: adolescent and older mothers, parity of three or more children and nulliparous women, low schooling, single marital status, mothers that did not work outside the home, cesarean delivery, delivery outside the hospital, prematurity, female gender, and non-white skin color. The strongest association was between low birth weight and prematurity $(\mathrm{OR}=35.93)$ 
Distribution of birth weight according to gestational age of live born infants. Information System on Live Births (SINASC), Rio Grande do Sul State, Brazil, 2003.

\begin{tabular}{|c|c|c|c|c|c|c|c|}
\hline & \multicolumn{6}{|c|}{ Gestational age (weeks) } & \multirow[t]{3}{*}{ Total $(\%)$ * } \\
\hline & \multicolumn{4}{|c|}{ Preterm } & \multirow{2}{*}{$\begin{array}{c}\text { Full-term } \\
37-41\end{array}$} & \multirow{2}{*}{$\begin{array}{c}\text { Post-term } \\
\geq 42\end{array}$} & \\
\hline & $22-27$ & $28-31$ & $32-36$ & $<37$ & & & \\
\hline \multicolumn{8}{|l|}{ Weight (g) } \\
\hline 500-999 & 371 & 161 & 26 & 558 & - & - & $558(0.4)$ \\
\hline $1,000-1,499$ & 127 & 517 & 413 & 1,057 & - & - & $1,057(0.7)$ \\
\hline $1,500-1,999$ & - & 337 & 1,539 & 1,876 & 278 & 2 & $2,156(1.5)$ \\
\hline $2,000-2,499$ & - & 55 & 3,066 & 3,121 & 5,296 & 24 & $8,441(5.8)$ \\
\hline $2,500-2,999$ & - & - & 2,893 & 2,893 & 32,490 & 284 & $35,667(24.5)$ \\
\hline $3,000-3,499$ & - & - & 1,136 & 1,136 & 58,471 & 604 & $60,211(41.4)$ \\
\hline $3,500-3,999$ & - & - & 186 & 186 & 29,852 & 453 & $30,491(20.9)$ \\
\hline$>4,000$ & - & - & 25 & 25 & 6,696 & 185 & $6,906(4.7)$ \\
\hline Total & 498 & 1,070 & 9,284 & 10,852 & 133,083 & 1,552 & $145,487(99.9)$ \\
\hline Low birth weight & 498 & 1,070 & 5,044 & 6,612 & 5,574 & 26 & 12,212 \\
\hline$\%$ & 100.0 & 100.0 & 54.3 & 60.9 & 4.2 & 1.7 & 8.4 \\
\hline
\end{tabular}

* 383 missing data for gestational age.

In multivariate logistic regression, skin color was not significantly associated with low birth weight $(\mathrm{p}=0.143)$ when the model was adjusted for live born infants, and was removed from the final model. Low birth weight was heavily determined by prematurity.

Table 3 shows crude and adjusted OR for fullterm live born infants. In the simple logistic regression, all the variables showed significant association with simplified small-for-gestational-age ( $p$ $<0.001$ ). The odds of being small-for-gestationalage in full-term live born infants with congenital anomalies were 2.75 higher than in full-term live born infants without anomalies. The odds of being small-for-gestational-age in live born infants of mothers with no prenatal were 2.63 higher than for infants of mothers with 7 or more visits. The odds of being small-for-gestational-age among live born infants of mothers with 0 to 3 years of schooling were 1.8 higher than for mothers with 12 or more years of schooling. According to multivariate logistic regression, type of delivery was not significantly associated $(\mathrm{p}=0.242)$ and was excluded from the model. Congenital anomaly was the variable that best explained small-forgestational-age, followed by number of prenatal visits and place of birth. In this case, when premature newborns were removed from the model, adolescent mothers, 4 to 11 years of maternal schooling, and skin color showed significant risk and remained in the model.

Table 4 shows the adjusted random-intercept multilevel models for all live births (models 1 and 2) and for full-term live births (model 3).

No evidence of extra-binomial dispersion was found in the three models, i.e., variation at the individual level in the hierarchical structure of the models without covariates did not show significant evidence that the data failed to present a binomial distribution.

In the multilevel modeling of all live births and full-term live births, the separately tested contextual variables urbanization rate, water supply, and sanitation were significant with the significant individual-level variables. Since these three variables were correlated ( $p<0.05)$, we chose to maintain urbanization rate in the model, since it showed the greatest statistical significance for the coefficient and greatest reduction in level 2 variance, besides being an indicator with the broadest meaning for representing the micro-region. The urbanization rate was categorized as follows: the lowest tertile (68.33\% urbanization or less) to measure risk for low birth weight and above this tertile as the reference bracket. The urbanization rate showed a protective effect, i.e., lower urbanization of the micro-region protected live born infants from low birth weight. 
Table 2

Simple and multivariate logistic regression for singleton live born infants with low birth weight. Information System on Live Births (SINASC), Rio Grande do Sul State, Brazil, 2003 ( $n=145,870)$.

\begin{tabular}{|c|c|c|c|c|}
\hline Independent variables & Total (\%) & Low birth weight (\%) & Crude OR $(95 \% \mathrm{Cl})$ & Adjusted OR $(95 \% \mathrm{Cl})$ \\
\hline \multicolumn{5}{|l|}{ Maternal age (years) } \\
\hline $20-34$ & $97,652(66.9)$ & $7,468(7.6)$ & 1.00 & 1.00 \\
\hline$\geq 35$ & 20,059 (13.8) & $1,985(9.9)$ & $1,33(1.26-1.40)$ & $1.35(1.26-1.45)$ \\
\hline$<20$ & $28,119(19.3)$ & $2,800(10.0)$ & $1.34(1.28-1.40)$ & $1.05(0.98-1.13)$ * \\
\hline \multicolumn{5}{|l|}{ Parity } \\
\hline $1-2$ & $58,608(43.5)$ & $4,103(7.0)$ & 1.00 & 1.00 \\
\hline Nulliparous & $54,290(40.2)$ & $5,046(9.3)$ & $1.36(1.30-1.42)$ & $1.43(1.35-1.51)$ \\
\hline$\geq 3$ & $22,041(16.3)$ & $2,171(9.8)$ & $1.45(1.37-1.53)$ & $1.20(1.11-1.29)$ \\
\hline \multicolumn{5}{|l|}{ Schooling (years) } \\
\hline$\geq 12$ & $22,147(15.3)$ & $1,621(7.3)$ & 1.00 & 1.00 \\
\hline $4-11$ & $110,156(75.9)$ & $9,309(8.5)$ & $1.17(1.11-1.24)$ & $1.08(1.00-1.17)$ * \\
\hline $0-3$ & $12,774(8.8)$ & $1,234(9.7)$ & $1.35(1.25-1.46)$ & $1.20(1.07-1.33)$ \\
\hline \multicolumn{5}{|l|}{ Marital status } \\
\hline Married & $55.609(38.2)$ & $4,023(7.2)$ & 1.00 & 1.00 \\
\hline Other & $89,802(61.8)$ & $8,199(9.1)$ & $1,29(1.24-1.34)$ & $1.13(1.07-1.19)$ \\
\hline \multicolumn{5}{|l|}{ Occupation } \\
\hline Other & $54,721(40.4)$ & $4,127(7.5)$ & 1.00 & 1.00 \\
\hline Housewife & $80,840(59.6)$ & $7,200(8.9)$ & $1.20(1.15-1.25)$ & $1.16(1.10-1.22)$ \\
\hline \multicolumn{5}{|l|}{ Prenatal visits } \\
\hline$\geq 7$ & $86,929(59.8)$ & $5,287(6.1)$ & 1.00 & 1.00 \\
\hline $1-6$ & $54,565(37.6)$ & 6,161 (11.3) & $1,97(1.89-2.04)$ & $1.57(1.49-1.65)$ \\
\hline None & $3,723(2.6)$ & $733(19.7)$ & $3.79(3.48-4.12)$ & $2.67(2.35-3.02)$ \\
\hline \multicolumn{5}{|l|}{ Type of delivery } \\
\hline Vaginal & $81,091(55.6)$ & $6,589(8.1)$ & 1.00 & 1.00 \\
\hline Cesarean & $64,774(44.4)$ & $5,667(8.7)$ & $1.08(1.05-1.13)$ & $1.10(1.04-1.15)$ \\
\hline \multicolumn{5}{|l|}{ Place of delivery } \\
\hline Hospital & $145,279(99.6)$ & $12,133(8.4)$ & 1.00 & 1.00 \\
\hline Other & $590(0.4)$ & $123(20.8)$ & $2.89(2.37-3.53)$ & $1.74(1.27-2.37)$ \\
\hline \multicolumn{5}{|l|}{ Gestational age } \\
\hline Full-term ( $\geq 37$ weeks) & $134,635(92.5)$ & $5,600(4.2)$ & 1.00 & 1.00 \\
\hline Preterm (<37 weeks) & $10,852(7.5)$ & $6,612(60.9)$ & $35.93(34.29-37.66)$ & $34.59(32.82-36.46)$ \\
\hline \multicolumn{5}{|l|}{ Sex } \\
\hline Male & $75,039(51.4)$ & $5,684(7.6)$ & 1.00 & 1.00 \\
\hline Female & $70,825(48.6)$ & $6,570(9.3)$ & $1.25(1.20-1.30)$ & $1.40(1.33-1.47)$ \\
\hline \multicolumn{5}{|l|}{ Skin color } \\
\hline White & $129,977(89.2)$ & $10,703(8.2)$ & 1.00 & - \\
\hline Other & $15,720(10.8)$ & $1,529(9.7)$ & $1.20(1.14-1.27)$ & - \\
\hline \multicolumn{5}{|l|}{ Congenital anomalies } \\
\hline No & $144.077(99.2)$ & $11,931(8.3)$ & 1.00 & 1.00 \\
\hline Yes & $1,170(0.8)$ & $260(22.2)$ & $3.17(2.75-3.64)$ & $2.22(1.81-2.74)$ \\
\hline Total & $145,870(100.0)$ & $12,257(8.4)$ & - & - \\
\hline
\end{tabular}

95\% Cl: 95\% confidence interval; OR: odds ratio.

Excludes cases with missing information: maternal age (40); parity (10,931); schooling (793); marital status (459); occupation (10,309); skin color (173); prenatal visits (653); type of delivery (5); place of delivery (1); gestational age (383); sex (6); and anomalies (623).

$p<0.001$ for independent variables, except * (not significant at 0.05 ). 


\section{Table 3}

Results of simple and multivariate logistic regression using low birth weight in full-term live born infants as the outcome * ( $n=134,635)$. Information System on Live Births (SINASC), Rio Grande do Sul State, Brazil, 2003.

\begin{tabular}{|c|c|c|}
\hline Variable & Crude OR $(95 \% \mathrm{Cl})$ & Adjusted OR $(95 \% \mathrm{Cl})$ \\
\hline \multicolumn{3}{|c|}{ Maternal age (years) } \\
\hline 20-34 & 1.00 & 1.00 \\
\hline$\geq 35$ & $1.31(1.21-1.41)$ & $1.41(1.30-1.54)$ \\
\hline$<20$ & $1.38(1.29-1.47)$ & $1.12(1.03-1.21)$ \\
\hline \multicolumn{3}{|l|}{ Parity } \\
\hline $1-2$ & 1.00 & 1.00 \\
\hline Nulliparous & $1.33(1.25-1.41)$ & $1.43(1.33-1.54)$ \\
\hline$\geq 3$ & $1.51(1.40-1.63)$ & $1.21(1.11-1.32)$ \\
\hline \multicolumn{3}{|c|}{ Schooling (years) } \\
\hline$\geq 12$ & 1.00 & 1.00 \\
\hline $4-11$ & $1.35(1.24-1.47)$ & $1.15(1.05-1.27)$ \\
\hline $0-3$ & $1.81(1.62-2.02)$ & $1.42(1.25-1.62)$ \\
\hline \multicolumn{3}{|l|}{ Marital status } \\
\hline Married & 1.00 & 1.00 \\
\hline Other & $1.29(1.21-1.36)$ & $1.10(1.03-1.18)$ \\
\hline \multicolumn{3}{|l|}{ Occupation } \\
\hline Other & 1.00 & 1.00 \\
\hline Housewife & $1.27(1.19-1.34)$ & $1.15(1.08-1.23)$ \\
\hline \multicolumn{3}{|l|}{ Prenatal visits } \\
\hline$\geq 7$ & 1.00 & 1.00 \\
\hline $1-6$ & $1.54(1.46-1.63)$ & $1.45(1.36-1.54)$ \\
\hline None & $2.63(2.31-3.01)$ & $2.34(2.01-2.72)$ \\
\hline \multicolumn{3}{|l|}{ Type of delivery } \\
\hline Vaginal & 1.00 & - \\
\hline Cesarean & $0.89(0.85-0.94)$ & - \\
\hline \multicolumn{3}{|c|}{ Place of delivery } \\
\hline Hospital & 1.00 & 1.00 \\
\hline Other & $3.37(2.56-4.44)$ & $2.26(1.64-3.13)$ \\
\hline \multicolumn{3}{|l|}{ Sex } \\
\hline Male & 1.00 & 1.00 \\
\hline Female & $1.52(1.44-1.61)$ & $1.52(1.43-1.61)$ \\
\hline \multicolumn{3}{|l|}{ Skin color } \\
\hline White & 1.00 & 1.00 \\
\hline Other & $1.24(1.15-1.35)$ & $1.11(1.02-1.22)$ \\
\hline \multicolumn{3}{|c|}{ Congenital anomalies } \\
\hline No & 1.00 & 1.00 \\
\hline Yes & $2.75(2.24-2.40)$ & $2.54(1.99-3.23)$ \\
\hline
\end{tabular}

95\% Cl: 95\% confidence interval; OR: odds ratio, simple analyses: $p<0.02$ for significant independent variables.

* Full-term live born infants ( $\geq 37$ weeks) defined as full-term live born infants ( 37 to 41 weeks) plus post-term live born infants ( $\geq 42$ weeks). 
Table 4

Models with effects of individual and contextual variables for risk of low birth weight.

\begin{tabular}{|c|c|c|c|}
\hline Variables & Model 1 - overall & Model 2 - overall & Model 3 - full-term \\
\hline \multicolumn{4}{|l|}{ Individual level } \\
\hline \multicolumn{4}{|l|}{ Maternal age (years) } \\
\hline $20-34$ & 1.00 & 1.00 & 1.00 \\
\hline$\geq 35$ & $1.35(1.26-1.46)$ & $1.35(1.26-1.45)$ & $1.39(1.28-1.52)$ \\
\hline$<20$ & $1.05(0.98-1.12)$ * & $1.05(0.98-1.12)$ * & $1.05(0.98-1.12)$ * \\
\hline \multicolumn{4}{|l|}{ Parity } \\
\hline $1-2$ & 1.00 & 1.00 & 1.00 \\
\hline Nulliparous & $1.43(1.34-1.51)$ & $1.42(1.34-1.51)$ & $1.41(1.31-1.52)$ \\
\hline$\geq 3$ & $1.20(1.12-1.29)$ & $1.20(1.12-1.29)$ & $1.21(1.11-1.32)$ \\
\hline \multicolumn{4}{|l|}{ Schooling (years) } \\
\hline$\geq 12$ & 1.00 & 1.00 & 1.00 \\
\hline $4-11$ & $1.08(1.00-1.17)$ * & $1.09(1.01-1.18)$ & $1.14(1.03-1.26)$ \\
\hline $0-3$ & $1.22(1.09-1.36)$ & $1.22(1.09-1.36)$ & $1.41(1.23-1.61)$ \\
\hline \multicolumn{4}{|l|}{ Marital status } \\
\hline Married & 1.00 & 1.00 & 1.00 \\
\hline Other & $1.15(1.08-1.21)$ & $1.10(1.04-1.17)$ & $1.09(1.01-1.17)$ \\
\hline \multicolumn{4}{|l|}{ Occupation } \\
\hline Other & 1.00 & 1.00 & 1.00 \\
\hline Housewife & $1.14(1.07-1.20)$ & $1.13(1.07-1.20)$ & $1.13(1.06-1.21)$ \\
\hline \multicolumn{4}{|l|}{ Prenatal visits } \\
\hline$\geq 7$ & 1.00 & 1.00 & 1.00 \\
\hline $1-6$ & $1.57(1.49-1.65)$ & $1.57(1.49-1.65)$ & $1.46(1.37-1.56)$ \\
\hline None & $2.70(2.38-3.06)$ & $2.70(2.39-3.07)$ & $2.39(2.05-2.80)$ \\
\hline \multicolumn{4}{|l|}{ Type of delivery } \\
\hline Vaginal & 1.00 & 1.00 & - \\
\hline Cesarean & $1.09(1.03-1.15)$ & $1.09(1.03-1.15)$ & - \\
\hline \multicolumn{4}{|l|}{ Place of delivery } \\
\hline Hospital & 1.00 & 1.00 & 1.00 \\
\hline Other & $1.70(1.25-2.33)$ & $1.71(1.25-2.33)$ & $2.16(1.54-3.03)$ \\
\hline \multicolumn{4}{|l|}{ Gestational age } \\
\hline Full-term ( $\geq 37$ weeks) & 1.00 & 1.00 & - \\
\hline Preterm (<37 weeks) & 35.95 (34.09-37.90) & 35.95 (34.09-37.90) & - \\
\hline \multicolumn{4}{|l|}{ Sex } \\
\hline Male & 1.00 & 1.00 & 1.00 \\
\hline Female & $1.40(1.33-1.47)$ & $1.40(1.33-1.47)$ & $1.52(1.43-1.62)$ \\
\hline \multicolumn{4}{|l|}{ Skin color } \\
\hline White & - & - & 1.00 \\
\hline Other & - & - & $1.14(1.04-1.25)$ \\
\hline \multicolumn{4}{|l|}{ Congenital anomalies } \\
\hline No & 1.00 & 1.00 & 1.00 \\
\hline Yes & $2.25(1.82-2.78)$ & $2.24(1.82-2.77)$ & $2.61(2.04-3.33)$ \\
\hline \multicolumn{4}{|l|}{ Contextual level } \\
\hline Lower urbanization ** & $0.82(0.69-0.97)$ & $0.70(0.59-0.83)$ & $0.73(0.61-0.88)$ \\
\hline Urbanization + marital status & - & $1.32(1.13-1.54)$ & $1.27(1.05-1.54)$ \\
\hline Variance $\left(\sigma^{2} \mathrm{uo}\right)$ & $0.041(p<0.01)$ & $0.040(p<0.01)$ & $0.017(p=0.017)$ \\
\hline DIC & $50,602.32$ & $50,590.88$ & $37,390.21$ \\
\hline
\end{tabular}

DIC: Deviance Information Criterion; Model 1: live born infants, random intercept, and without interaction; Model 2: live born infants, random intercept, and with interaction; Model 3: full-term live born infants, random intercept, and with interaction.

* Not significant at 0.05 ;

** Urbanization rate $=\%$ of population in the urban area. 
No random effect was found in the urbanization rate variable as verified by the random coefficient test. The model is thus one of variance component, since only the intercept was random.

To assess the effect of possible interactions between the individual and contextual variables in the final model, the variables age, schooling, number of prenatal visits, and parity were dichotomized to facilitate interpretation.

The interaction between urbanization and marital status showed a significant risk in models 2 and 3 , indicating that unmarried mothers living in less urbanized micro-regions showed higher risk of low birth weight.

For model 1, inclusion of the urbanization rate reduced the variance in the contextual level by $18 \%$, and in model 2 , which included the interaction between urbanization and marital status, variance reduced by $20 \%$. Thus, for model 2 , the estimated intra-micro-regions correlation coefficient $(\rho)$ was $1.5 \%$, showing the degree to which variation in low birth weight was due to variation between micro-regions, indicating that most variation in low birth weight $(98.5 \%)$ occurred at the individual level. Model 2 (with interaction) was the better of the two models for live births, since it showed the lowest DIC.

For model 3 of full-term live born infants, inclusion of the urbanization rate reduced the variance in the contextual level by $19 \%$; with the inclusion of the interaction between urbanization and marital status, contextual level variance was maintained. For this model, the intra-micro-regions correlation coefficient $(\rho)$ was $0.6 \%$ less than in the models for all live births. In this model, adolescent mothers did not show a risk of small-for-gestational-age infants, contrary to the classical model (Table 3).

The residuals analysis for model 2 identified three micro-regions with increased risk of low birth weight (above the overall mean), Carazinho, Passo Fundo, and Serras do Sudeste, and five micro-regions with lower risk than the overall mean, Restinga Seca, Santiago, Campanha Central, Santa Maria, and Porto Alegre. The other micro-regions showed residuals with no significant difference from the overall mean.

In model 3, the Caxias do Sul and Carazinho micro-regions showed an increased risk of smallfor-gestational-age infants as compared to the mean. Meanwhile, Porto Alegre and Santa Maria showed lower risk of small-for-gestational-age in full-term live born infants.

\section{Discussion}

Although the data showed a significant hierarchical structure, a small difference was observed in the estimated coefficient between the classical and multilevel models, since variation in low birth weight occurred more between the live born infants and less between the micro-regions. Even with the small difference, consideration of the hierarchy in the data's structure showed that the micro-region's urbanization rate significantly affected the risk of low birth weight, so the multilevel model was superior to the classical one 12 .

To ignore this structure would mean overlooking the effect of the micro-region's urbanization on the risk of low birth weight in live born infants 12 .

Incidence of low birth weight was $8.4 \%$, lower than the rate for Rio Grande do Sul (9.52\%) in 2003, obtained from the SINASC data base, since the latter includes multiple pregnancies and does not limit weight or gestational age.

The SINASC data were evaluated as satisfactory, since the percentage of unknown or missing information was no greater than $9.9 \% 17$.

This study found the following risk factors associated with low birth weight using the classical multiple logistic regression model: prematurity, zero or 1 to 6 prenatal visits, congenital anomaly, non-hospital delivery, high and low parity, female gender, maternal age greater than 35 years, housewife, unmarried, low schooling ( 0 to 3 years) and cesarean delivery, while skin color was not statistically significant. A study on low birth weight in Goiânia, capital of the State of Goiás, Brazil, by Giglio et al. 18 showed similar findings. Minamisawa et al. 19, in a study with data from the State of Goiás, showed similar results, except for cesarean delivery, which showed a protective effect against low birth weight, and whose prevalence $(44.5 \%)$ was similar to our study.

In the classical regression model for full-term live born infants, the risk factors for low birth weight (simplified small-for-gestational-age) were somewhat higher than for live births as a whole, and adolescent mothers, 4 to 11 years of maternal schooling, and non-white skin color showed a significant effect in the model, which did not occur with live births as a whole. These brackets are indicative of lower socioeconomic status, which is known to be associated with intrauterine growth restriction. The model indicated that cesarean delivery was not a risk for simplified small-for-gestational-age, suggesting that cesareans were associated with prematurity. The fact that cesarean delivery was a risk factor for low birth weight in the group of all live births but not full-term live births indicated that cesar- 
eans were mostly being performed in premature live born infants, although there is no consensus in the literature as to whether it is the best form of delivery in these cases 20 .

Small-for-gestational-age is used as an indicator of intrauterine growth restriction, but this simplified classification can underestimate the true number of live born infants with intrauterine growth restriction 9 .

For all live births, four to 11 years of maternal schooling was a risk factor for low birth weight in the multilevel model, but not in the classical model. Lower urbanization was a protective factor, and interaction between lower urbanization and single marital status was a risk factor for low birth weight, which was also observed for fullterm live births.

The multilevel model showed greater risk of low birth weight for infants of mothers living in more urbanized micro-regions. The association was not adjusted for smoking, alcohol, or illicit drug use during pregnancy, which may explain the finding. Inclusion of interaction improved the model's quality and indicated that in less urbanized micro-regions, risk of low birth weight increased for unmarried mothers.

Finding a significant association between the micro-region's urbanization and low birth weight reaffirms the existence of the "low birth weight epidemiological paradox", the term used for the fact that Mexican-American mothers with lower socioeconomic status show similar or lower low birth weight rates compared to white mothers in the United States. Brazilian data show a similar paradox: low birth weight rates are higher in the more developed regions of the country 21 . Less urbanized areas may protect live born infants from low birth weight due to less use of ultrasound tests, which can lead to errors in estimating gestational age, fewer cesarean deliveries based on clinical indications, better maternal nutrition, less maternal stress, possibly less smoking, alcohol, and illicit drug use during pregnancy, and more frequent occurrence of live births evaluated as stillbirths, which were not included in this study.

One multilevel study including urbanization was a longitudinal ecological study in the United States. According to the authors, urbanization was a protective factor against low birth weight, unlike the current study, in which greater urbanization showed increased risk of low birth weight 22 . These divergent findings may be explained by the "epidemiological paradox". The Caxias do Sul micro-region, one of the most developed in the State of Rio Grande do Sul, showed the highest risk of small-for-gestational-age.

The literature includes several multilevel studies on low birth weight, such as Jarvelin et al. 1 in Finland, showing that part of the residual variation was explained by the neighborhood's financial capacity, used as a contextual variable. Gestational age, sex, parity, maternal age, and other factors were strongly associated with birth weight, while education, social class, and marital status were not. A study by Gorman 23 in the United States showed that variation in low birth weight according to skin color was associated with maternal characteristics and place of residence.

O'Campo et al. 24 showed that the association between individual risk factors and low birth weight was moderated by neighborhood characteristics in Baltimore, Maryland. The impact of advanced maternal age on low birth weight was more pronounced under conditions of high unemployment in the neighborhood. All the individual-level risk factors showed interactions with variables at the macro level, i.e., they behaved differently according to the neighborhood's characteristics. In the multilevel model for Rio Grande do Sul State, the risk of advanced maternal age did not change, but maternal schooling did.

The skin color of live born infants as a whole was not associated with low birth weight, while for full-term live born infants it was a risk factor for small-for-gestational-age, with intrauterine growth restriction associated with non-white maternal skin color. Rich-Edwards et al. 25 , in Chicago, reported that mothers at extreme ages had an increased risk of low birth weight, which was more pronounced for black women, and the difference was explained by the economic deprivation of these mothers in the United States. Another study in Chicago by Buka et al. 26 showed similar findings for African-American mothers; white mothers showed a significant positive association between social support and birth weight, while for black mothers this support was not significant.

Another study on live born infants in Chicago by Morenoff 27 showed that mechanisms related to stress and coping, i.e., the occurrence of violent crimes, mutual exchanges (neighborhood associations in general), and participation in volunteer associations in the neighborhood were the most robust predictors of birth weight at the regional level. In the current study in Rio Grande do Sul State, homicide rate, hospitalization rate due to assault, used as proxies for level of violence, were not a risk factor for low birth weight. These indicators may not be the best for measuring violence, which could require more specific variables.

According to Thompson et al. 28 , low birth weight rates vary between regions of the United 
States, and although individual and contextual characteristics have an important impact on low birth weight, a significant part of the risk of low birth weight remains unexplained and is associated with maternal place of residence and perinatal and intra-partum care at the contextual level. The conclusion corroborates our findings.

The studies listed above support the hypothesis that factors associated with the mother's neighborhood are significantly associated with birth weight.

A multilevel study on low birth weight in Argentina by Hachuel et al. ${ }^{29}$ showed the following risk factors at the individual level: maternal age $>40$ years, primiparity, $\geq 5$ more prenatal visits, and spontaneous delivery (without forceps or other intervention). The fact that the estimated variance for mother's place of residence was not significant indicated the lack of variability that would have allowed evaluation of the multilevel model, so the model was limited to the individual level, unlike the current study's findings.

The current study's limitations included: (1) use of secondary data, impeding calculation of gestational age in weeks and data on smoking, alcohol, and illicit drug use during pregnancy; (2) size of groups at the contextual level (microregions), since very large groups involve wide internal variability, hindering the attribution of characteristics at this level 30; and (3) choice of micro-regions, which was based on the number of groups and availability of context indicators.

Based on this study's limitations, we recommend the inclusion of the specific gestational age on the live birth certificate rather than in brackets of weeks, as well as information on smoking, alcohol and illicit drug use, thus allowing a better understanding of the individual factors leading to low birth weight.

In the classical regression model, the intercept and slope coefficient are fixed parameters, i.e., they do not change, while in the multilevel model they are considered random parameters, i.e., able to vary in the units of the highest hierarchical level 31. Thus, the multilevel analyses take into account the impact of contextual variables on individual health outcomes, resulting in an important health policy-making tool 32 .

Low birth weight can be caused by various perinatal problems, most frequently by low gestational age. These findings may not apply to more specific causes of low birth weight, but the identification of differences in low birth weight between micro-regions of the state provides new direction for future research attempting to better explain such differences.

This study confirmed risk factors found in the literature and was the first multilevel modeling study on low birth weight using data from the State of Rio Grande do Sul.

\section{Resumo}

O objetivo deste estudo foi identificar os fatores de risco para o baixo peso ao nascer de nascidos vivos de gestação simples no Rio Grande do Sul, Brasil, em 2003, obtidos do Sistema de Informações sobre Nascidos Vivos. Foram utilizadas regressão logística múltipla clássica e multinível. Os fatores de risco foram avaliados no nível individual (nascidos vivos) e contextual (microrregiões). No nível individual dos dois modelos foi encontrada associação significativa entre baixo peso ao nascer e prematuridade, consultas pré-natais, anomalia congênita, local do nascimento, paridade, sexo, idade materna, ocupação materna, estado civil, escolaridade e tipo de parto. Nos modelos multiníveis, quanto maior a urbanização da microrregião maior o risco de baixo peso ao nascer, e, em microrregiões menos urbanizadas, mães solteiras têm risco aumentado, para todos os nascidos vivos. O baixo peso ao nascer varia com a microrregião e está associado a características individuais e contextuais. Embora a maior parte da variação no baixo peso ao nascer se encontre no nível individual, o modelo multinível identificou um fator de risco importante no nível contextual.

Recém-Nascido; Baixo Peso ao Nascer; Fatores de Risco 


\section{Contributors}

A. B. Moraes and R. R. Zanini contributed to the study design, data collection, analyses, and interpretations, and writing and final approval of the article. J. Riboldi and E. R. J. Giugliani collaborated with the orientation, writing, revision, and final approval of the article.

\section{References}

1. Jarvelin MR, Elliott P, Kleinschmidt I, Martuzzi M, Grundy C, Hartikainen AL, et al. Ecological and individual predictors of birthweight in a Northern Finland birth cohort 1986. Paediatr Perinat Epidemiol 1997; 11:298-312.

2. World Health Organization. Towards the development of a strategy for promoting optimal fetal growth. Geneva: World Health Organization; 2004.

3. Fondo de las Naciones Unidas para la Infancia. Progreso para la infancia - Bajo peso al nacer. http://www.unicef.org/spanish/progressfor children/2006n4/index_lowbirthweight.html? (accessed on $13 / \mathrm{Jul} / 2012$ )

4. Victora CG, Grassi PR, Schmidt AM. Situação de saúde da criança em área da região sul do Brasil, 1980-1992: tendências temporais e distribuição espacial. Rev Saúde Pública 1994; 28:23-32.

5. Barros AJD. Modelos multinível: primeiros passos. Pelotas: Departamento de Medicina Social, Faculdade de Medicina, Universidade Federal de Pelotas; 2001.

6. Diez-Roux AV. Bringing context back into epidemiology: variables and fallacies in multilevel analysis. Am J Public Health 1998; 88:216-22.

7. Souza LM. Avaliação do Sistema de Informação sobre Nascidos Vivos - SINASC, Minas Gerais e Mesoregiões, 2000 [Masters Thesis]. Belo Horizonte: Centro de Desenvolvimento e Planejamento Regional, Universidade Federal de Minas Gerais; 2004.
8. Margotto PR. Limite de viabilidade e legalidade, 2010. http:/www.paulomargotto.com.br/index sub.php?tipo=28 (accessed on 13/Jul/2012).

9. Costa CE, Gotlieb SLD. Estudo epidemiológico do peso ao nascer a partir da Declaração de Nascido Vivo. Rev Saúde Pública 1998; 32:328-34.

10. Hosmer Jr. DW, Lemeshow S. Applied logistic regression. New York: John Wiley \& Sons; 1989.

11. Fuchs SC, Victora CG, Fachel J. Modelo hierarquizado: uma proposta de modelagem aplicada à investigação de fatores de risco para diarréia grave. Rev Saúde Pública 1996; 30:168-78.

12. Rasbash J, Steele F, Browne W, Prosser B. A user's guide to MLwiN. Version 2.0. Bristol: Centre for Multilevel Modelling, University of Bristol; 2005.

13. Goldstein H. Multilevel statistical models. London Arnold; 2003.

14. Puente-Palacios KE, Laros JA. Análise multinível: contribuições para estudos sobre efeito do contexto social no comportamento individual. Estud Psicol (Campinas) 2009; 26:349-61.

15. Bryk AS, Raudenbush SW. Hierarchical linear models. Newbury Park: Sage; 1992.

16. Merlo J, Chaix B, Yang M, Lynch J, Rästam L. A brief conceptual tutorial of multilevel analysis in social epidemiology: linking the statistical concept of clustering to the idea of contextual phenomenon. J Epidemiol Community Health 2005; 59:443-9. 
17. Mello-Jorge MHPM, Gotlieb SLD, Oliveira H. O Sistema de Informação sobre Nascidos Vivos: 1a avaliação dos dados brasileiros. Inf Epidemiol SUS 1996; 2:78-89.

18. Giglio MRP, Lamounier JL, Morais Neto OL, César CC. Baixo peso ao nascer em coorte de recém-nascidos em Goiânia-Brasil no ano de 2000. Rev Bras Ginecol Obstet 2005; 27:130-6.

19. Minamisawa R, Barbosa MA, Malagoni L, Andraus LMS. Fatores associados ao baixo peso ao nascer no estado de Goiás. Rev Eletrônica Enferm 2004; 6:336-49. http://www.revistas.ufg.br/index.php/ fen/article/view/837/987.

20. Souza ASR, Amorim MMR, Porto AMF. Condições freqüentemente associadas com cesariana, sem respaldo científico. Femina 2010; 38:10.

21. Silva AAM, Bettiol H, Barbieri MA, Pereira MM, Brito LGO, Ribeiro VS, et al. Why are the low birthweight rates in Brazil higher in richer than in poorer municipalities? Exploring the epidemiological paradox of low birthweight. Paediatr Perinat Epidemiol 2005; 19:43-9.

22. Shi L, Macinko J, Starfield B, Xu J, Regan J, Politzer $\mathrm{R}$, et al. Primary care, infant mortality, and low birth weight in the states of the USA. J Epidemiol Community Health 2004; 58:374-80.

23. Gorman BK. Racial and ethnic variation in low birthweight in the United States: individual and contextual determinants. Health Place 1999; 5:195207.

24. O'Campo P, Xue X, Wang MC, Caughy MOB. Neighborhood risk factors for low birthweight in Baltimore: a multilevel analysis. Am J Public Health 1997; 87:1113-8.
25. Rich-Edwards JW, Buka SL, Brennan RT, Earls F. Diverging associations of maternal age with low birthweight for black and white mothers. Int J Epidemiol 2003; 32:83-90.

26. Buka SL, Brennan RT, Rich-Edwards JW, Raudenbush SW, Earls F. Neighborhood support and the birth weight of urban infants. Am J Epidemiol 2003; 157:1-8.

27. Morenoff JD. Neighborhood mechanisms and the spatial dynamics of birth weight. AJS 2003; 108:976-1017.

28. Thompson LA, Goodman DC, Chang CH, Stukel TA. Regional variation in rates of low birth weight. Pediatrics 2005; 116:1114-21.

29. Hachuel L, Boggio G, Borra V. Uso de modelos logit mixtos para el estudio del bajo peso al nacer en Rosario. In: Undécimas Jornadas “Investigaciones en la Faculdad” de Ciencias Económicas y Estadística. http://www.fcecon.unr.edu.ar/fcecon.unr. edu.ar/sites/default/files/u16/Decimocuartas/ Hachuel_L,\%20uso\%20de\%20modelos\%20logit. pdf/ (accessed on 12/Sep/2012).

30. Ellen IG, Mijanovich T, Dillman KN. Neighborhood effects on health: exploring the links and assessing the evidence. J Urban Affairs 2001; 23:391-408.

31. Soares TM, Mendonça MCM. Construção de um modelo de regressão hierárquico para os dados do SIMAVE-2000. Pesquisa Operacional 2003; 23: 421-41.

32. O'Campo P. Invited commentary: advancing theory and methods for multilevel models of residential neighborhoods and health. Am J Epidemiol 2003; 157:9-17.

Submitted on 23/Feb/2012

Final version resubmitted on 13/Jul/2012

Approved on 30/Aug/2012 